\title{
On Becoming a Zebra
}

\section{Nicole Martinez*}

Doctor of Psychology, Licensed Clinical Professional Counselor, USA

"In making the diagnosis of the cause of illness in an individual case, calculations of probability have no meaning. The pertinent question is whether the disease is present or not. Whether it is rare or common does not change the odds in a single patient. ... If the diagnosis can be made on the basis of specific criteria, then these criteria are either fulfilled or not fulfilled."-A. McGehee Harvey, James Bordley II, Jeremiah Barondess. Zebra is the American medical slang for arriving at an exotic medical diagnosis when a more common place explanation is more likely. It is shorthand for a quote of the late 1940s by Dr. Theodore Woodward, professor at the University Of Maryland School Of Medicine, who instructed his medical interns: "When you hear hoof beats, think of horses not zebras". Since horses are common in Maryland while zebras are relatively rare, logically one could confidently guess that an animal making hoof beats is probably a horse. This phrase continues to be taught to medical students. Wikipedia 2015. Diagnosticians have noted, however, that "zebra"type diagnoses must nonetheless be held in mind until the evidence conclusively rules them out. My journey started 15 months ago or 15 years ago depending on how you look at it. , but it feels like a lifetime. I am almost 40, and it was not until about 15 years ago that I started to have allergic reactions. I had allergy tests that pinpointed specific things I was supposedly allergic too, I had numerous urgent care and Emergency Room (ER) visits for severe allergic reactions for all those years. We made assumptions I was exposed to a certain allergen and added them to the list. As the years went on, the list of positive allergy tests grew and grew, but was I really allergic to these things, or did they have something in common?

Along with this came the debilitating fatigue, the extreme muscle, joint and bone pain, add another diagnosis. Constant strange blood test results indicating any number of disorders and diseases, add a few more in, but never a certainty [1-5]. I also always held the belief that it was not likely that I had numerous varied disorders, syndromes, and diseases, but rather one that explained it all. I was right, but it would take some time to piece it all together. I had a weak immune system, and everyone knew I was not kidding when I said I would catch what they had if they came near me. Who gets meningitis twice, pneumonia every other year, bronchitis often twice a year, and countless sinus infections? I do. It took someone to finally ask that question and not just treat it to figure it out. We figured out after my eventual diagnosis, which I will be getting too, that I also had the added bonus of being born without immunities to HIB, pneumonia and meningitis. Many vaccinations, like a newborn, later, and I have an "adequate immune system, just over the acceptable line. So why do I say 15 months, ago or 15 years? Well I have shared what the last 15 years looked like and grew too. However the last 15 months have changed my life in every imaginable way. It was Mother's Day, and I just had not been feeling right all day. I took my mother out to the Drake for Mother's Day Afternoon Tea, a lovely treat. Throughout our day there I took my inhaler several times, and was just not feeling right. I was dropped off at home and walked through the yard to the house. I walked in, sat on my bed, and said to me husband, I can't breathe, take me to the ER. Something I have never said. He rushed me there, and what proceeded was a sight that he says he will never forget. I went into anaphylaxis, had angioedema, giant hives, my throat was having bronchospasm and swelled up. I was given any number of medications that were not helping. The ER attending called in someone from ICU. My husband sat helpless watching very concerned doctors struggling to stabilize me. They finally did, and I was admitted, for the first time of more to come. We found out that this day was the highest pollen count in history, and thought maybe that set it off. However, that did not explain the hives all over my arms for 6 days prior. In retrospect, I should have addressed it. When I was released, I was told to go back to the ER if I even got hives. 2 weeks later, hives and breathing issues, so back to the ER as instructed. This time I was treated as somewhat of a nuisance. Treatment for an allergic reaction and anaphylaxis, and eye roll from someone who gave me a breathing treatment to the nurse, which of course they thought I did not see. I get it, you fixed the problem, and there are more dire cases to move on to. One week later, back to the ER with Anaphylaxis, swollen up and bright purple. Emergency meds work, and I was given the option of admission or to go home with meds hours later. I chose home. Not even two weeks later, sitting in my office at work and swell up like a pumpkin, walk down the hall with my epi pen in hand and ask if it is as bad as I think. Ambulance was called right away. I received some emergency treatment in the ambulance, and more at the ER. I was told within 20 minutes of arriving there, that I was going to be admitted. This doctor seemed very interested in figuring out what was causing these life threatening reactions, and admitted me and diagnosed me with an anaphylactic reaction on the side of the notes I could see. On the side I was not supposed to see, an implication was made that maybe I was giving myself something to induce the reactions. Really????? Because the mystery was not solved in our small window together, that must be the culprit. I still struggle with that knowledge to this day, and it breaks my heart for anyone else who was accused or discounted in this way. One week later my life was changed again. We were living in fear of another reaction, and of the medications not working one of these times. A colleague asked if they could get my records and send them to a specialist in something called Mast Cell Diseases. I would do anything at this point, so I said please do. 12 hours later I was making the drive out of state to a specialty facility, 36 hours later I was seen by someone who promised me they would figure this out, and knew exactly what they were looking for. Me and my husband cried at their certainty and reassurance, it had been a rough road. I spent two weeks there, had more tests than I can count, was diagnosed, and went home with a plan to stabilize me as much as is possible. I was connected with an amazing local doctor, and was their first patient with my disorder. They were amazing, and learned as much as they could get their hands on, they still do. I feel in safe hands, and I know I am getting the right treatment. Are there still drawbacks? Yes. I was sent for a consult, and

*Corresponding author: Nicole M. Martinez, Doctor of Psychology, Licensed Clinical Professional Counselor, USA, Tel: 8479758316; E-mail: nmmartinez1313@gmail.com

Received July 15, 2015; Accepted August 29, 2015; Published September 05 2015

Citation: Martinez N (2015) On Becoming a Zebra. J Psychiatry 18: 321 doi 10.4172/2378-5756.1000321

Copyright: () 2015 Martinez N. This is an open-access article distributed under the terms of the Creative Commons Attribution License, which permits unrestricted use, distribution, and reproduction in any medium, provided the original author and source are credited 
without reading my records, the person immediately tried to prove I was not a Zebra. That I could not have what I have, before reading my records and test results. Reading it changed things, but I still left I tears. It brought me back to the scary unknown times, to the one ER doctor, to fearing for my life, but I was reassured to let that all go by my main doctor. That I would never have to see this person again. Did I mention they were citing 20 year old criteria that has been dramatically changed? I have to take a multitude of medications and treatments. One of the drugs that help me the most is what is called an Orphan Drug. What is this? This is a drug that is not approved by the FDA, but is allowed to be brought in the country to treat Zebra's like me. It is brought in from Canada, sent to a pharmacy in Washington, where it is compounded, and then mailed to me. I of course must pay out of pocket for it, as it is not FDA approved. It is not FDA approved because not enough people have the disease to make it worth their while, and it has been used in other countries for 15-20 years, so the money making patents have expired. So no real motivation or incentive to approve it here. I now work from home, as I can best contain my environment, and I had flair ups too often to be fair to my employers, co-workers or clients. It remains a struggle to completely stabilize me, but I am much better than I was. My husband has been the most incredible person, but the life he thought we would have when we got married 3.5 years ago is very different. My life as completely changed, and that can be a lot to handle sometimes.

In medicine, the term "zebra" is used in reference to a rare disease or condition. Doctors are taught to assume that the simplest explanation is usually correct to avoid patients being misdiagnosed with rare illnesses. Doctors learn to expect common conditions. But some medical professionals seem to forget that "zebras" DO exist and so getting a diagnosis and treatment can be more difficult for sufferers of rare conditions. The road to diagnosis can be filled with anxiety, depression, hopelessness, and anger. Mast Cell Diseases are considered rare conditions and so Mast Cell Disease sufferers are known as medical zebras. This identity has now been adopted across the world through social media to help bring our community together. Getting to know my community has been one of the most supportive, welcoming, and rewarding things to come out of this experience. We have the Mastocytosis (Mast Cell Disease) Society that is very active in research, has support pages and forums, innumerable resources, and holds an annual conference that doctors, patients, and caregivers can all attend. For many, this sense of community, and the support groups, are a lifeline, but sometimes they are not enough. Many patients need, and could greatly benefit from individual psychotherapy. "There are close to 7,000 rare diseases that affect 30 million Americans ("About NORD")." "In the process of searching for a diagnosis, patients with rare diseases will find themselves in countless doctors' offices, often waiting years for a diagnosis and treatment. Healthcare professionals will most likely encounter patients with rare diseases on a daily basis, but the lack of knowledge of specific rare diseases makes many health practitioner-patient interactions frustrating, or even life-threatening if the medical professional is unaware of the severity of problems caused by a rare disease." During this period, when a medical diagnosis has not been discovered, many of these patients are referred for psychological services, as many doctors will believe it is a psychological issue and not an organic one. This can be frustrating, humiliating, and shaming to the patient that is seeking help and an answer. They know their bodies, they know something is wrong, and they feel they have nowhere to turn.

So now therapists have patients looking for a diagnosis, failing to get a diagnosis, getting a diagnosis, and adjusting to major life changes due to their diagnosis. Patients often have a stronger interest in their diseases because "for patients with a rare disorder, the disease is no longer rare- it is a constant part of their lives and the life of their families". Medical problems that previously carried considerable mortality risk can now be managed more effectively. As a result, chronic medical illnesses have become more prevalent in recent years. With the increase in life expectancy comes a set of psychological challenges that face the chronically ill. Chronic disease is associated with high levels of uncertainty. Patients need to change their behavior as part of a new lifestyle of self-care. They also have to endure debilitating and demanding treatments. These are some of the factors that make adjustment to chronic medical illness psychologically demanding. It is generally accepted that around a quarter of patients with chronic medical problems have clinically significant psychological symptoms. In some cases, these psychological symptoms themselves are associated with physical morbidity. Even in the absence of overt psychological or psychiatric disorder, patients have to regulate oftencomplex and ever-changing thoughts, feelings, and behaviors. This type of therapy is well suited for the chronically ill, and those with rare diseases, and it has been empirically proven to be effective. It can address the issue related to mood, fatigue, a general feeling of being physically unwell. It can help patients be more assertive advocates for themselves with healthcare professionals, to make sure they are being heard. This is an important piece, as many had a difficult time with this in the long road to diagnosis. A hallmark of the therapy is skill building to help the patient with disease management. White discussed 4 essential components of the therapy, which still hold true today. They are: Agenda setting, self-monitoring, experimentation, and changing distressing thoughts. Agenda setting is the encouraging the patient to make lists that are clear and focused about what they hope to cover with the physician during the visit. This helps to reduce frustration for the patient and the physician, it assures nothing important is left out, it provides structure to the appointment, and it helps you and the physician identify priorities and a plan.

Self-monitoring are tasks such as keeping a mood, medication and food journal. This can record fluctuations and issues that the patient might not remember amongst the many things they discuss in a checkup. This helps them to remember, and to see patterns. The types of monitoring assignments to be given could be endless. Experimentation is when you ask the patient to try, track, and report back on situations and factors that might be exacerbating and flaring up their symptoms. For example, a fight with a family member or partner my trigger symptoms in the individual. If the connection is made, steps can be made to change the way they deal with things, or not put themselves in certain situations that are likely to have a bad outcome. Lastly is the exercise of changing distressing thoughts. "Cognitive therapy usually involves the modification of thoughts and behaviors that seem to be contributing to a patient's symptoms." The therapist can challenge their distressing thought and replace it with a healthier and more realistic one. This can have a profound impact on the patient's well-being. I think it is clear that psychological services are not only effective, but are also essential to patients who are struggling for diagnosis, adjusting to a new diagnosis, or living with a chronic or rare illness.

\section{References}

1. About NORD. (n.d.). Retrieved from https://www.rarediseases.org/about

2. Griggs RC, Batshaw M, Dunkle M, Gopal-Srivastava R, Kaye E, et al (2009) Clinical research for rare disease: Opportunities, challenges, and solutions. Molecular Genetics and Metabolism, 96(1), 20-26. Retrieved from http://dx.doi.org.proxy.library.emory.edu/10.1016/j.ymgme.2008.10.003 
3. Hull, Anna (February 16, 2014). Of Rare Disease and Zebras. Sick: Healthcare in the Modern Era. The Official Blog of the University Course from Emory University on Healthcare Delivery. Sponsored by the Center for Faculty Development and Excellence Rare disease. (n.d.). Retrieved from http:// ndriresource.org/Human-Tissue-Services/Rare-Disease/30/
4. Rare disease database. (n.d.). Retrieved from https://www.rarediseases.org/ rare-disease-information/rare-diseases

5. White, Craig (2001) Cognitive Behavioral Principles in Managing Chronic Disease. Western Journal of Medicine 175 (5): 338-342. 